Book Review

\title{
COVID -19: Introductory Handbook in Homoeopathy
}

\section{Sita Ram Sharma and Bindu Sharma}

Sub-title: "The Health of Humanity is at Stake"

Language: English

Published by: B. Jain Publishers (P) Ltd., India

Pages: 124

The "COVID -19: Introductory Handbook in Homoeopathy" is a handbook written in the wake of the situation evolved from the new life-threatening viral disease by the name of COVID-19. This book has been brought out at a time when the most scientific system of medicine is looking for a solution for this grave condition.

The book is divided into six sections. In the introductory part of this handbook, the authors have explicitly stated about the H1N1 virus, updated information on Corona virus, the disease condition, its implications and how homoeopathic treatment has proved effective and gave better results than conventional system of medicines in various epidemics such as cholera, spanish flu, etc. In further section, the clinical details of the present disease condition, its management regarding the conventional system, preventive measures, diet regimen to boost immunity, related myths and the facts have been brought out in very modest manner. In the next chapters the Homoeopathic concept of prevention and treatment has been described. Understanding the gravity of this disease condition, the authors have also given guidelines for the physicians to run their clinic. It contains Homoeopathic therapeutics with respect to various stages of COVID-19 and a short repertory as a ready reckoner. A very vital part i.e. 'References' are mentioned at end of each chapter so that the reader may go back to the source book or material.

Few more books related to SARS-CoV-2 have been published. However, this book has its own uniqueness. It reminds us of the teachings of Dr. Hahnemann that a physician should have knowledge of the disease, what is curable in the disease and knowledge of medicine to treat the disease. The homoeopathic therapeutics are given comprehensively and the repertory in the form of symptom index gives a broad outline.

This book has been so well written and in such a subtle manner that it can be read and understood by a student, a professional, a physician, or even a common man who is interested to know about this disease condition and how homoeopathy can be beneficial. The whole concept and directions given in the book will be extremely useful for the clinicians, students, and researchers at par.

One of the authors is a former scientist and the co-author is working as scientist - 4 in Central Council for Research in Homoeopathy, under Ministry of AYUSH, Govt. of India. They both have expertise in the field of research and vast clinical experience, emphasized on 'Evidence based practice' and advocated for 'Integrative approach' for the prevention and treatment of cases of COVID-19.

This book is distinctive as the information available is well researched and authentic. However, this book may require updatings and come out in form of a new edition as the pathophysiology, the symptomatology and complications of the neo-virus are still evolving and so are the treatment modalities in the conventional system. The homoeopathic therapeutics may also increase or vary accordingly. 
The book has been published by B. Jain Publishers (P) Ltd., Noida (UP), India. The font and spacing is good enough for a comfortable reading. The book is worth 249 INR. All said and done, this piece of work is worth reading and can be purchased online at Amazon.

Amazon link: https://www.amazon.in/COVID-19-Introductory-Handbook-HomoeopathySharma/dp/8131915530

\section{PRITHA MEHRA}

Central Council for Research in Homoeopathy, New Delhi, India, www.ccrhindia.nic.in

drpritha@gmail.com; prithamehra@ccrhindia.nic.in

https://orcid.org/0000-0003-3551-5816

Received: Oct 22, 2020. Accepted: Oct 23, 2020.

(C) International Journal of High Dilution Research.

Not for commercial purposes.

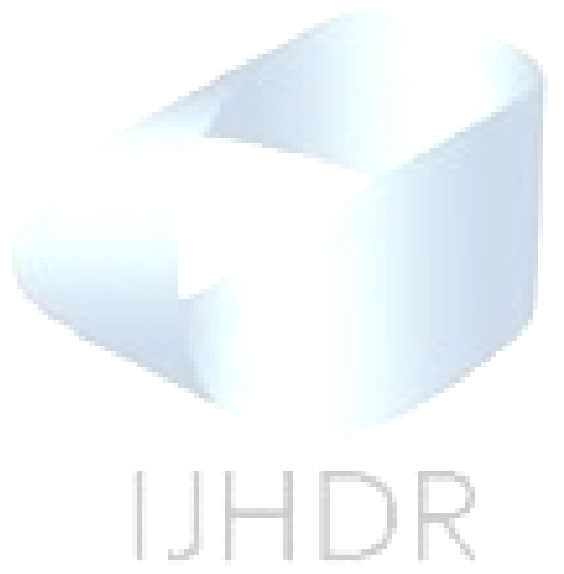

